Резнік В.С, к.ф-м.н, с.н.с.

Обгрунтування застосування нелінійної моделі в'язкопружності типу моделі Работнова в задачах повзучості

Інститут механіки С.П. Тимошенка НАН

України, вул. Нестерова, 3, 03057, Київ; e-mail creep@inmech.kiev.ua
V.S. Reznik, Ph.D. (Phys.-Math.), Sci. researcher.

\section{Justification of application of nonlinear viscoelasticity model of Rabotnov's model type in creep problems}

S.P. Timoshenko Institute of Mechanics, 252680,

Nesterov str, 3, Kiev;

e-mail creep@inmech.kiev.ua

Залежність між компонентами тензора деформацій, тензора напружень $і$ часом задається за допомогою визначальних рівнянь спадкового типу, щзо записані виходячи з гіпотези пропориійності девіаторів. В якості об'єкту дослідження розглядаються тонкостінні трубчасті елементи з поліетилену низького тиску. Обгрунтовується область застосування моделі виходячи з гіпотези існування єдиної діаграми миттєвого деформування $і$ єдиної діаграми довготривалого деформування. Перевірясться інваріантність діаграм розтягу і кручення відносно напруженого стану. Визнається область нелінійно-пружного деформування. Визначальні рівняння моделі містять набір функиій $і$ коефіцієнтів, щзо визначаються з базових експериментів. Розроблено метод визначення параметрів ядер спадковості нелінійно в'язкопружних матеріалів за умов складного напруженого стану. Нелінійність в'язкопружних властивостей задається рівняннями типу моделі Работнова. Метод трунтується на співвідношеннях між ядрами повзучості, що отримані за умов складного напруженого стану і ядрами повзучості за умов одновимірного напруженого стану. Метод апробуються експериментально на задачах розрахунку деформачій повзучості при комбінованому навантаженні тонкостінних трубчатих елементів з поліетилени низького тиску.

Ключові слова: нелінійна в'язкопружність, складний напружений стан, діаграма миттєвого деформування, діаграма кручення, повздовжня повзучість, зсувна повзучість, об'ємна повзучість, ядра спадковості, ізохронні діаграми.

The relationship between the components of the strain tensor, stress tensor and time is given by the defining equations of the hereditary type, which are written based on the hypothesis of proportionality of the deviators. Thin-walled tubular low-pressure polyethylene elements are considered as the object of research. The scope of the model is substantiated based on the hypothesis of the existence of a single diagram of instantaneous deformation and a single diagram of long-term deformation. The invariance of the tensile and torsion diagrams with respect to the stress state is checked. The region of nonlinear elastic deformation is determined. The defining equations of the model contain a set of functions and coefficients determined from the basic experiments. A method for determining the parameters of heredity kernels of nonlinear viscoelastic materials under complex stress state has been developed. The nonlinearity of viscoelastic properties is given by equations of the Rabotnov's model type. The method is based on the relations between the creep kernels obtained under conditions of complex stress state and the creep kernels under one-dimensional stress state. The method is tested experimentally on the problems of calculating creep deformations under combined loading of thin-walled tubular elements made of low-pressure polyethylene

Key words: nonlinear visco-elasticity, complex stressed state, longitudinal creep, shearing creep, volume creep, diagrams of instant deformation, diagrams of torsion, longitudinal creep, shear creep, volume creep, heredity nuclei, isochronous diagrams.

Статтю представив член-кор. НАН України Жук Я.О.

(C) В.С. Резнік, 2021 


\section{Вступ}

Широке застосування тонкостінних трубчастих елементів 3 полімерних матеріалів зумовило детальне вивчення їх в'язкопружних властивостей. Багато елементів конструкцій являють собою об'єкти, що деформуються за умов складного напруженого стану. Найчастіше деформування в'язкопружних середовищ задають за допомогою рівнянь спадкового типу [1-2]. Рівняння встановлюють залежність між компонентами тензора деформацій, тензора напружень і часовим інтегральним оператором, i містять ядра спадковості, набір функцій i коефіцієнтів, що визначаються із базових експериментів.

Однією 3 гіпотез, що використана при побудові визначальних рівнянь за умов складного напруженого стану $\epsilon$ гіпотеза пропорційності девіаторів тензорів. В рамках цієі гіпотези в роботі [3] побудовано систему визначальних рівнянь для нелінійних в'язкопружних середовищ. В роботі [4] ядра спадковості за умов складного напруженого стану визначаються за ядрами повздовжньої i поперечної повзучості.

В даній статті обгрунтовується область застосування моделі виходячи 3 гіпотези існування єдиної діаграми миттєвого деформування і єдиної діаграми довготривалого деформування. Перевіряється інваріантність діаграм розтягу i кручення відносно напруженого стану. Визнається область нелінійно-пружного деформування. Розроблено метод визначення параметрів ядер спадковості нелінійно в'язкопружних матері-алів за умов складного напруженого стану.

\section{1. Постановка задачі}

В роботі розглядається деформування ізотропних нелінійно-в'язкопружних середо-вищ зі стабільними механіченими властивостями за умов складного напруженого стану із заданою програмою навантаження, так що

$$
\sigma_{i j}(\tau), \quad \tau \in(0, t)
$$

де $\sigma_{i j}$ - компоненти тензора напружень; $t$ - час спостереження; $\tau$-час, що передує моменту спостереження. Процес навантаження (1) вважаємо простим, так що виконуються співвідношення

$$
\sigma_{11}=\mu(t) \bar{\sigma}_{11}, \ldots, \tau_{12}=\mu(t) \bar{\sigma}_{12}, \ldots
$$

Визначальні рівняння що задають залежність між компонентами тензора деформацій $\varepsilon_{i j}(t)$ i компонентами тензора напружень $\sigma_{i j}(t)$ при повзучості запишемо у вигляді [3]

$$
\left\{\begin{array}{l}
\varepsilon_{i j}(t)-\frac{1}{3} \delta_{i j} \varepsilon_{v}(t)=\frac{3}{2} \frac{\varepsilon_{i}\left(\sigma_{i}(t) ; t\right)}{\sigma_{i}(t)}\left(\sigma_{i j}(t)-\delta_{i j} \sigma_{0}(t)\right), \\
\varphi_{i}\left(\varepsilon_{i}(t)\right)=\sigma_{i}(t)+\lambda_{i} \int_{0}^{t} K_{i}(t-\tau) \sigma_{i}(\tau) d \tau ; \\
\varphi_{v}\left(\varepsilon_{v}(t)\right)=\sigma_{0}(t)+\lambda_{v} \int_{0}^{t} K_{v}(t-\tau) \sigma_{0}(\tau) d \tau,
\end{array}\right.
$$

де $\varepsilon_{v}(\cdot)$ i $\varepsilon_{i}(\cdot)$ - об'ємна деформація i інтенсивність тензора деформацій; $\sigma_{0}(t)$ і $\sigma_{i}(t)$ - перший інваріант i інтенсивність тензора напружень, $\delta_{i j}$ - дельта-функція Кронекера, $\varphi_{i}(\cdot)$ і $\varphi_{v}(\cdot)$ - функції, що задають нелінійність скалярних властивостей; $K_{i}(\cdot), K_{v}(\cdot), \lambda_{i}, \lambda_{v}-$ реологічні параметри.

Нелінійність в'язкопружних властивостей в рівнянні (2) задається функціями $\varphi_{i}(\cdot)$ і $\varphi_{v}(\cdot)$, які задовольняють гіпотезі єдиної діаграми короткотривалого деформування в координатах „інтенсивність напружень $\sigma_{i}$ - інтенсивність деформацій $\varepsilon_{i}$ ” $\mathrm{i}$,середнє напруження $\sigma_{0}$ об'ємна деформація $\varepsilon_{v}$ ".

Вважається, що діаграми короткотривалого деформування інваріантні по відношенню до виду напруженого стану.

Задача полягає у обгруванні область застосування моделі виходячи 3 гіпотези існування єдиної діаграми миттєвого деформування і єдиної діаграми довготривалого деформування, апробації інваріантності діаграм розтягу і кручення відносно напруженого стану, визначенні області нелінійно-пружного деформування. Визначенні параметрів ядер спадковості нелінійно в'язкопружних матеріалів за умов складного напруженого стану та апробації отриманих залежностей між ядрами на задачах розрахунку деформацій повзучості та релаксації напружень.

\section{2.Обгрунтування застосування нелінійної моделі в'язкопружності}

Існування єдиної діаграми миттєвого деформування обгрунтовується за результатами короткотривалих випробовувань тонкостінних трубчатих зразків на одновісний розтяг i чисте кручення. Вирази для інтенсивності напружень i деформацій за умов одновісного розтягу мають вигляд 


$$
\sigma_{i}=\sigma_{11} ; \quad \varepsilon_{i}=\varepsilon_{11}-\frac{1-2 v}{3 E} \sigma_{11},
$$

а за умов чистого кручення -вигляд

$$
\sigma_{i}=\sqrt{3} \tau_{21} ; \quad \varepsilon_{i}=\frac{2}{\sqrt{3}} \varepsilon_{21} .
$$

Тут $E$ - модуль пружності; $v$ - коефіцієнт Пуассона.

На рис. 1. представлено залежності

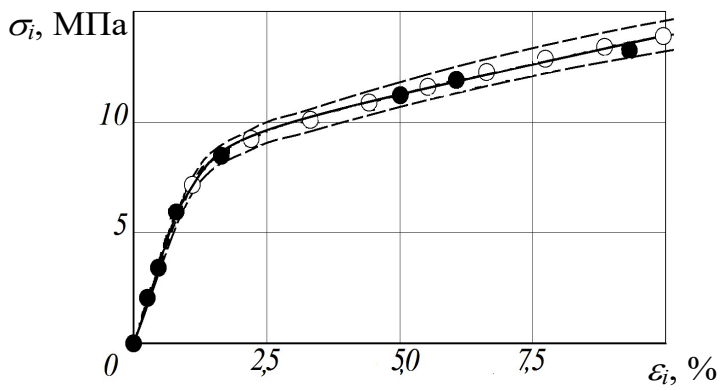

Рис. 1 - Едина діаграма «миттєвого» деформування поліетилену низького тиску за умов одновісногорозтягу(о)і чистого кручення $(\bullet)$

інтенсивності нормальних напружень від інтенсивносі лінійних деформацій для поліетилену низького тиску. Залежності побудовано за результатами випробувань тонкостінних трубчатих зразків 3 використанням співвідношень (3) і (4). В цілому, як показує рис.1, гіпотеза існування єдиної діаграми «миттєваго» деформування для поліетилену низького тиску підтверджується. Практично всі точки, що відповідають залежностям $\sigma_{i}$ від $\varepsilon_{i}$, не виходять за межі інтервалу, обмеженого величиною $\delta= \pm 5 \%$.

3. Едина діаграма довготривалого деформування Із факту існвання единої діаграми «миттєвого» деформування випливає, що залежність інтенсивності

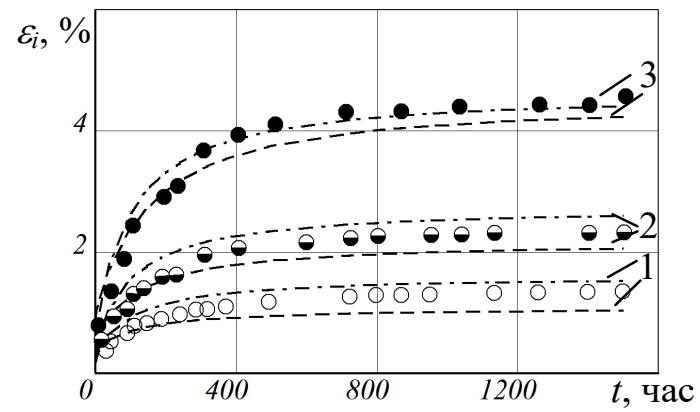

Рис. 2 - Едина діаграма довготривалого деформування поліетилену низького тиску при $\sigma_{i}=2,59$ $(\circ, 1) ; 3,92(\bullet, 2) ; 5,88(\bullet, 3)$ МПа.- — діаграма, що відповідає одновісному розтягу;-- - д діаграма, що відповідає чистому крученню напружень від інтенсивності деформацій може бути визначена за результатами випробувань на одновісний розтяг. В цьому випадку вирази для інтенсивності напружень і деформацій за умов одновісного розтягу і чистого кручення задаються згідно (3) і (4), а при комбінованому навантаженні розтягом 3 крученням запишемо у вигляді

$$
\begin{aligned}
\sigma_{i} & =\sqrt{\sigma_{11}^{2}+3 \tau_{21}^{2}} ; \\
\varepsilon_{i} & =\frac{2}{\sqrt{3}} \sqrt{\left(\varepsilon_{11}-\varepsilon_{22}\right)^{2}+\left(\varepsilon_{33}-\varepsilon_{11}\right)^{2}+6 \varepsilon_{21}^{2}}
\end{aligned}
$$

де $\varepsilon_{22}=\varepsilon_{33}-$ поперечні деформації. Інші позначення співпадають з прйнятими в (3) і (4).

На рис.2 представлено залежності інтенсивності деформацій повзучості від часу для поліетилену низького тиску. Штрихо-вими лініями нанесено залежності інтенсив-ностей деформацій повзучості від часу за умов одновісного розтягу, а штрихпунктирними ліниями-за умов чистого кручення. Як свідчить рис. 2, для поліетилену низького тиску підтверджується також i гіпотеза існування єдиної діаграми довготривалого деформування в координатах « $\varepsilon_{i}-t »$. Значення інтенсивностей деформацій $\varepsilon_{i}(t)$, отримані за умов комбінованого навантаження розтягом 3 крученням (точки), практично співпадають із значеннями $\varepsilon_{i}(t)$, отриманими за умов чистого розтягу (штрихові лінії). Очевидно, що вид i параметри функціональної залежності, що задає єдину діаграму довготривалого деформування, може бути визначена за результатами випробувань на одновісну повзучість.

4. Розрахунок деформацій повзучості за умов складного напруженого стану

Вибір структури ядра здійснено
виходячи is мінімуму квадратичного відхилення дискретних значень ядер від їх аналітичних виразів. В роботі в якості ядра спадковості використано дробовоекспоненціальне ядро

$$
K(t-\tau)=\frac{1}{(t-\tau)^{-\alpha}} \sum_{n=0}^{\infty} \frac{(-\beta)^{n}(t-\tau)^{n(1+\alpha)}}{\Gamma[(1+n)(1+\alpha)]} ;
$$


де $\alpha$ i $\beta$ - параметри ядер $(-1<\alpha<0 ; \quad \beta>0) ; \Gamma[\cdot]$ - гамма-функція.

Між ядрами, що знайдені за умов складного напруженого стану і ядрами, що знайдені за умов одновимірного напруженого стану існує зв’язок, що виражається формулами:

$$
\lambda_{i} K_{i}(t)=\frac{2}{3} \frac{\psi_{11}\left(\sigma_{11}\right) \lambda_{11} K_{11}(t)+\psi_{22}\left(\sigma_{11}\right) \lambda_{22} K_{22}(t)}{\psi_{i}\left(\sigma_{i}\right)}
$$$$
\lambda_{v} K_{v}(t)=\frac{\psi_{11}\left(\sigma_{11}\right) \lambda_{11} K_{11}(t)+2 \psi_{22}\left(\sigma_{11}\right) \lambda_{22} K_{22}(t)}{\psi_{v}\left(\frac{1}{3} \sigma_{11}\right)}
$$

або формулами

$$
\lambda_{i} K_{i}(t)=\lambda_{12} K_{12}(t),
$$$$
\lambda_{v} K_{v}(t)=\frac{3 \lambda_{11} K_{11}(t) \psi_{11}\left(\sigma_{11}(\tau)\right)-2 \sqrt{3} \lambda_{12} K_{12}(t) \psi_{12}\left(\frac{\sigma_{11}(\tau)}{\sqrt{3}}\right)}{3 \psi_{11}\left(\sigma_{11}(t)\right)-2 \sqrt{3} \psi_{12}\left(\frac{\sigma_{11}(t)}{\sqrt{3}}\right)}
$$

Для компонент тензора деформацій $\varepsilon_{i j}(t)$

із системи рівнянь (2) 3 врахуванням (6) отримаємо рівняння

$$
\begin{aligned}
& \varepsilon_{i j}(t)=\frac{3}{2} \frac{1}{\sigma_{i}(t)} \psi_{i}\left[\sigma_{i}(t)+\lambda_{i} \int_{0}^{t} \frac{\left(-\beta_{i}\right)^{n}(t-\tau)^{\left(1+\alpha_{i}\right) n}}{\Gamma\left[(1+n)\left(1+\alpha_{i}\right)\right]} \sigma_{i}(\tau) d \tau\right] \times \\
& {\left[\sigma_{i j}(t)-\delta_{i j} \sigma_{0}(t)\right]+\frac{1}{3} \delta_{i j} \psi_{v}\left[\sigma_{0}(t)+\lambda_{v} \int_{0}^{t} \frac{\left(-\beta_{v}\right)^{n}(t-\tau)^{\left(1+\alpha_{v}\right) n}}{\Gamma\left[(1+n)\left(1+\alpha_{v}\right)\right]} \sigma_{0}(\tau) d \tau\right]}
\end{aligned}
$$

Результати розрахунків за рівнянням (9) за умов складного напруженого стану, виконаних з використанням параметрів ядер, що знайдені за даними випробувань на повзу-

\section{Список використаних джерел}

1. Работнов Ю. H. Ползучесть элементов 1. RABOTNOV U.N. (1966) Polzuchest' elementov конструкций.- Москва: Наука, 1966. - 752 с.

2. Кристенсен P.M. Введение в теорию 2. KRISTENSEN R.M. (1974). Vvedenie v teoriu вязкоупругости//Пер. с англ. под ред. Г.С.Шапиро. - Москва: Мир, 1974. - 340 с.

3. Голуб В. П., Кобзарь Ю. М., Рагулина В. С. К задаче определения параметров ядер наследственности изотропных нелинейновязкоупругих материалов при сложном напряженном состоянии // Теорет. и прик. механика. - 2013. - №5(51). - С. 26-35.

4. Голуб В.П., Кобзарь Ю.М., Фернати П.В. К решению задач ползучести изотропных нелинейно-вязкоупругих материалов при сложном напряженном состоянии // Теор и прикл. механика.- 2014.- Вып 8 (54).- С. 45-56

Наукові дослідження, результати яких опубліковано в даній статті, виконано за рахунок коштів бюджетної програми »Підтримка пріоритетнихнатрямівнауковихдосліфюень» (КПКВК 6541230).

Надійшла до редколегії 22.06.2021 чість за умов одновісного розтягу з заміром поздовжніх і поперечних деформацій повзучості нанесені штриховими лініями. Штрихпунктирними лініями нанесені результати розрахунків, виконаних 3 використанням параметрів ядер, які знай-дені за даними випробувань на повзучість за умов одновісного розтягу з заміром повздовжніх деформацій і при чистому крученні 3 заміром зсувних деформацій.

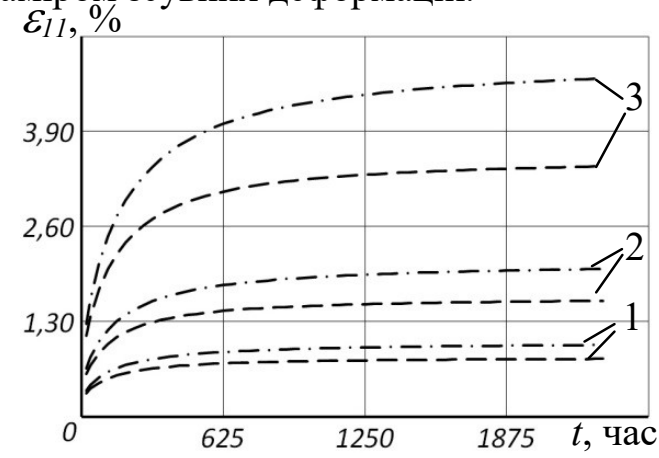

Рис.3.Розрахункові лінії деформації повздовжньої повзучості тонкостінних трубчастих елементів 3 поліетилену низького тиску за умов одночасної дії розтягу 3 крученням. $\sigma_{11}=1,96, \tau_{21}=0,98(1) ; \sigma_{11}=2,97, \tau_{21}=$ $1,48(2) ; \sigma_{11}=4,45, \tau_{21}=2,23$ (3) МПа.

3 рис. 3 маємо, що розрахунки кожним підходом при невеликих значеннях напружень дають практично однакові результати, а при більших значеннях розбіжність складає близько $20 \%$. vyazkouprugosti// Moskva: Mir.

3. GOLUB V.P. KOBZAR U.M. RAGULINA V.S. (2013). K zadache opredeleniya parametrov yader nasledstvennosri izotropnih nelineynovyazkouprugih materialov pri slognom napryagennom sostoyanii // Teoret. $i$ prikl. mehanika. - №5(51). - p. 26-35.

4. GOLUB V.P. KOBZAR U.M. FERNATI P.V. (2014). K resheniu zadach polzuchesti izotropnih nelineyno-vyazkouprugih materialov pri slognom napryagennom sostoyanii // Teoret. i prikl. mehanika. - №5(51). - p. 26-35. 